\title{
ACERCA DEL CONTROL SOCIAL DE LA GESTIÓN PÚBLICA
}

\author{
Carlos E. Delpiazzo
}

\section{RESUMEN}

Después de analisar la ley anticorrupción de Uruguay, el autor destaca los aspectos positivos, aseverando la necesidad da ética en la administración publica; si administrar quiere decir servir, el funcionários es un servidor y la ética es exigencia mínima es exigencia mínima a quien desempeña tal función de tan relevante interes, aunque sea la más modesta de las tareas.

Palabras clave: Administración pública. Corrupción. Ética.

\section{INTRODUCCION}

Con distintos matices y grados de intensidad, se asiste hoy en el mundo a transformaciones de la Administración, con proyecciones relevantes sobre el control de su funcionamiento por parte de la sociedad'. No resulta ajeno a dichos cambios el "rescate de lo ético" en la actuación de los servidores públicos ${ }^{2}$, no limitándose a la prevención o reacción frente a la corrupción sino garantizando la vigencia y realización de todos los valores éticos en el ámbito administrativo, fundados en la trascendencia de la persona y en el carácter servicial de la Administración ya que, "en definitiva, es la dignidad humana la que marcará las pautas de conducta. Dignidad en el administrador y en el administrado, en el que realiza las funciones administrativas y en su destinatario"3.

Por eso, bien se ha dicho que, en lo que refiere a la Administración pública, a las tres "e" que se han puesto de moda con los procesos de reforma y modernización estatal -economía, eficiencia y eficacia- se agrega últimamente una cuarta "e", correspondiente a la ética ${ }^{4}$.

Ahora bien: para que la sociedad y sus integrantes puedan controlar adecuadamente a la Administración como servidora que es de todos los componentes del cuerpo social, se requiere que su actuación sea transparente a sus ojos. Control social y transparencia son pues, los términos de la cuestión sobre la que se reflexionará seguidamente. 


\section{ACERCA DEL CONTROL SOCIAL}

\subsection{Dimensión conceptual}

En un sentido amplio, puede considerarse al control como la "comprobación de regularidad de una función propia 0 ajena"5. De tal caracterización surgen con nitidez los dos componentes básicos que lo configuran, a saber:

a) una función (premisa menor) entendida ampliamente como comprensiva de toda tarea, trabajo o actividad; $y$

b) un conjunto de normas (premisa mayor) también entendidas éstas en sentido amplio, o sea, cualquiera sea su naturaleza (jurídicas o no) según las cuales aquélla ha de desenvolverse.

Por eso, antes de ahora ${ }^{6}$, siguiendo a la mejor doctrina nacional ${ }^{7}$, he enfatizado que el control de una actividad supone un juicio lógico respecto a si dicha actividad se conforma o no a las reglas que la regulan.

Dicho juicio constituye la exteriorización de esa comprobación de regularidad a través de un auténtico silogismo y como tal hace parte de uno de los tres elementos esenciales del control ${ }^{8}$, a saber:

a) los poderes o medios de información mediante los cuales el controlante toma conocimiento de la actividad que desarrolla el órgano o el funcionario controlado;

b) el procedimiento de control en sentido estricto, es decir, el modo o forma en que el controlante emite un pronunciamiento (favorable o desfavorable) acerca de la actividad controlada; y

c) los efectos y la eventual ejecución del juicio de comprobación.

En consecuencia, puede decirse que el control discurre ordinariamente a través de tres momentos ${ }^{9}$ o fases ${ }^{10}$, a saber:

a) un momento preparatorio o de toma de información;

b) un momento lógico o nuclear en el cual se emite el juicio o manifestación de conocimiento acerca de si la actividad controlada se ajusta o no a las reglas que la regulan; y

c) un momento conminatorio de carácter eventual ya que sólo se dará cuando el juicio haya sido desfavorable o negativo y, por ende, deba ser seguido de una medida que corrija o elimine la irregularidad constatada por cuanto, en caso contrario, o sea, cuando el juicio haya resultado favorable o positivo, la actuación quedará terminada con el momento lógico. 
Cuando se habla de control social de la Administración, se alude a una especie dentro del género de los controles, cual es la que se ejercita por parte de la sociedad, enfatizando en la naturaleza instrumental ${ }^{11}$ o servicial ${ }^{12}$ del Estado para el logro del bien común, de su ser para otros ${ }^{13}$, a fin de que los componentes del cuerpo social -todos- puedan alcanzar plenamente sus fines propios.

\subsection{Dimensión positiva}

Bajo la denominación de "Control social", el capítulo III de la ley anticorrupción № 17.060 de 23 de diciembre de 1998 contiene tres disposiciones jerarquizadoras del principio de transparencia en el obrar de los servidores públicos ${ }^{14}$.

En primer término, el art. $5^{\circ}$ ordena que "Los organismos públicos darán amplia publicidad a sus adquisiciones de bienes y contrataciones de servicios".

A renglón seguido, establece el art. 6으 que "El Poder Ejecutivo, a propuesta de la Junta (Asesora en Materia Económico Financiera del Estado creada en la misma ley), llevará a cabo periódicamente campañas de difusión en materia de transparencia pública y responsabilidad de los funcionarios públicos, así como sobre los delitos contra la Administración Pública y los mecanismos de control ciudadano".

Finalmente, agrega el art. $7^{0}$ que "Los actos, documentos y demás elementos relativos a la función pública pueden ser divulgados libremente, salvo que por su naturaleza deban permanecer reservados o secretos o hayan sido declarados tales por ley o resolución fundada. En todo caso, bajo la responsabilidad a que hubiere lugar por Derecho".

Obsérvese que la normativa transcripta pone el énfasis en el acceso por los integrantes del cuerpo social a la información relativa al quehacer administrativo, avanzando un paso más respecto a la clásica publicidad de su actividad al prever que esa información pueda ser divulgada libremente por el medio que sea ${ }^{15}$. Se ingresa así en el amplio campo del nuevo principio general de transparencia.

\section{ENFOQUE DE LA TRANSPARENCIA}

\subsection{Dimensión conceptual}

Intimamente asociado al principio de publicidad $^{16}$, el principio de transparencia supone algo más. Cuando se habla de transparencia de la gestión administrativa, "se quiere dar un paso más respecto a la publicidad... como que la publicidad implica mostrar pero la transparencia implica algo más que mostrar, 
implica dejar ver; simplemente que el actuar de la Administración se deje ver como a través de un cristal"17.

Según se ha destacado con acierto, el principio de publicidad deriva de la forma republicana de gobierno ${ }^{18}$ y "las restricciones a la publicidad deben atender a dos criterios: por un lado, deben ser más débiles cuanto mayor sea el interés individual del que pide información; por otro lado, deben ser más débiles cuanto mayor sea la responsabilidad del solicitante por el buen funcionamiento del ente administrativo requerido. $Y$ en ambos casos, la restricción debe ser motivada en una razón que sea suficientemente importante como para compensar la razón genérica que aconseja la publicidad como resorte esencial del sistema republicano. No hay que olvidar que la restricción debe tener siempre un motivo legítimo, derivar de un acto inspirado en alguna razón atendible... Pero si no hay razones para la restricción, aunque tampoco existan motivos especiales para la publicidad, ésta procede; precisamente porque ésta es la solución de principio bajo el sistema republicano"19.

Más allá de la publicidad, la transparencia refiere a la diafanidad del obrar público, permitiendo ver con claridad el actuar de la Administración en la disposición y uso de los fondos públicos y en el obrar de sus funcionarios; "constituye una consecuencia de la muy elemental presunción de que el gobierno pertenece al pueblo, quien tiene derecho a saber qué hacen los servidores públicos, por qué y cómo lo hacen"20.

Se trata de subrayar cómo la sociedad quiere que sea la Administración de principios del siglo XXI: no sólo debe servir sino que debe mostrar cómo sirve, lo cual exige que sea abierta a la información, a la participación y al control democrático, con un funcionamiento transparente que la transforme en una verdadera casa de cristal.

Según se ha destacado ${ }^{21}$, la transparencia se asocia a lo que es visible y accesible, a lo que puede ser conocido y comprendido, por contraposición a lo cerrado, misterioso, inaccesible o inexplicable. Igualmente, la transparencia se asocia a una carga afectiva ligada a la tranquilidad y serenidad provocada por todo aquello que se domina y racionaliza, por oposición a la angustia y perturbación de lo misterioso y desconocido. Además, del contraste entre las sombras y la luz, entre opacidad y transparencia, nacen nuevos métodos que tratan de referir el principio de legalidad, como límite y fundamento de la acción administrativa, al principio de consecución del interés público y del respeto por los derechos de los ciudadanos en el marco del bien común, métodos que tratan de promover los principios de colaboración ciudadana, de participación y de promoción de una nueva y diferente forma de concebir el poder administrativo más próximo a los ciudadanos. 


\subsection{Dimensión positiva}

Aunque la operatividad de los principios generales de Derecho no está condicionada a su explicitación por normas positivas dado que participan de la idea básica de principialidad en sentido ontológico ${ }^{22}$, nuestro Derecho positivo reciente exhibe una marcada tendencia a su enumeración a través de disposiciones legales y reglamentarias ${ }^{23}$.

Por lo que refiere al principio de transparencia en el obrar público, interesa destacar especialmente su reconocimiento en el marco del ordenamiento dispuesto para prevenir y reprimir la corrupción ${ }^{24}$.

Así, la ley № 17.040 de 20 de noviembre de 1998 obliga a todas las empresas públicas o de propiedad estatal a publicar en la prensa y poner a disposición de los medios de comunicación su balance general, expresado en los estados de situación patrimonial y de resultados, en forma abierta y sencilla "para que el usuario no especializado pueda formarse un juicio cabal del servicio y de su tarifa" (art. $3^{\circ}$ ).

Por otra parte, ya ha quedado dicho que la ley № 17.060 , consecuente a la ratificación de la Convención Interamericana contra la Corrupción (CICC) por la ley № 17.008 de 25 de setiembre de 1998, vincula la transparencia al control -especialmente social- y a la responsabilidad, a la vez que la gestión administrativa no sólo se prevé que pueda ser conocida (a través de la publicidad de la información) sino que la misma pueda ser divulgada libremente a través de cualquier medio (atributo de la transparencia).

Igualmente, otras disposiciones vitalizadoras de la publicidad traducen más bien aplicaciones del principio de transparencia de la gestión pública en la medida que implican el conocimiento del quehacer de la Administración tal como éste se desenvuelve $y$, de ser posible, mientras se está desenvolviendo. Se trata de una "especificación" del principio de publicidad que demanda de la Administración una posición más servicial y receptiva ${ }^{25}$, jerarquizando el derecho a la información de que es titular la sociedad como tal y cada uno de sus integrantes.

\section{TRASCENDENCIA ETICA DE LA CUESTION}

\section{ético}

\subsection{El Derecho Administrativo como custodio del comportamiento}

Bien se ha dicho que "la ética pública es necesaria para reforzar las condiciones de credibilidad en la propia Administración pública y sus agentes, algo sustancial a la transparencia administrativa"26. 
El funcionario público que adecua su conducta al deber ser y actúa como un verdadero servidor público no tiene nada que ocultar ni a sus superiores ni a sus subordinados ni a los integrantes del cuerpo social a los que se debe en el desempeño de sus tareas presididas por el fin del logro del bien común.

En feliz expresión ajustada a la verdad, se ha configurado al Derecho Administrativo como "custodio del comportamiento ético", destacando que el mismo "trata de garantizar el servicio a los intereses generales, sujetando la actividad administrativa a una serie de formalidades y controles"27.

Tratando de evitar en lo posible el uso del poder para fines distintos a aquellos en que se concreta el interés público, esta rama del Derecho contempla una serie de medidas respecto a las personas llamadas al desempeño de la función pública, tanto en el momento de acceder a ella, como durante su desempeño, y aún después de su cese ${ }^{28}$.

De acuerdo al art. 20 de la ley № 17.060, "Los funcionarios públicos deberán observar estrictamente el principio de probidad, que implica una conducta funcional honesta en el desempeño del cargo con preeminencia del interés público sobre cualquier otro" (inc. 1ํ). Agrega que "El interés público se expresa en la satisfacción de necesidades colectivas de manera regular y continua, en la buena fe en el ejercicio del poder, en la imparcialidad de las decisiones adoptadas, en el desempeño de las atribuciones y obligaciones funcionales, en la rectitud de su ejercicio y en la idónea administración de los recursos públicos" (inc. 2º̄).

Obsérvese que cuando así se describe el obrar funcional, desde el punto de vista del control por la sociedad el énfasis está puesto más que en un juicio lógico de carácter jurídico, en un juicio lógico de carácter ético ya que las reglas (premisa mayor) respecto a las cuales se encuadrará el juzgamiento de lo actuado (premisa menor) provienen de la ética. No obstante, se verifica -por la incorporación en normas positivas- una juridización de la ética.

\subsection{Virtudes y vicios en la función pública}

Como se ha señalado con acierto, en el quehacer de la Administración, "la idea de servicio de los intereses generales debe presidir la actuación de cualquiera que realiza una función pública. Autoridad o funcionario, político o empleado, debe hacer siempre lo que sea mejor para los intereses públicos"29.

Pero la dimensión ética no se agota en la fidelidad a los intereses generales sino que reclama el trabajo bien hecho. Para ello, se requiere cultivar las virtudes -que son hábitos operativos buenos que se alcanzan mediante esfuerzo, lucha y educación- y luchar contra los defectos que todo lo echan a perder -corrupción significa echar a perder o pudrir- ya que una sociedad que se acostumbra a prácticas y actitudes torcidas, termina pudriéndose ${ }^{30}$.

Precisamente, el principio de transparencia tiene una fuerza ética especial en la medida que propende al desarrollo de conductas funcionales honradas, de 
"hombres de bien" que, al decir del art. 59 de la Constitución, actúan sobre "la base fundamental de que el funcionario existe para la función y no la función para el funcionario". Y siendo así, nada tienen que esconder.

El art. 21 de la multicitada ley № 17.060 enuncia algunas de las virtudes del buen funcionario al establecer que "Los funcionarios públicos observarán los principios de respeto, imparcialidad, rectitud e idoneidad y evitarán toda conducta que comporte un abuso, exceso o desviación de poder, y el uso indebido de su cargo o su intervención en asuntos que puedan beneficiarlos económicamente 0 beneficiar a personas relacionadas directamente con ellos".

A la inversa, el art. 22 de la misma ley configura como conductas "contrarias a la probidad en la función pública", entre otras, las siguientes:

a) negar información o documentación que haya sido solicitada en conformidad a la ley;

b) valerse del cargo para influir sobre una persona con el objeto de conseguir un beneficio directo o indirecto para sí o para un tercero;

c) tomar en préstamo o bajo cualquier otra forma dinero o bienes de la institución, salvo que la ley expresamente lo autorice;

d) intervenir en las decisiones que recaigan en asuntos en que hayan participado como técnicos; y

e) usar en beneficio propio o de terceros información reservada o privilegiada de la que se tenga conocimiento en el ejercicio de su función.

Consecuentemente, antes de ahora ${ }^{31}$, destaqué que, en el ámbito de la función administrativa, son necesarias la generosidad, la fortaleza, el optimismo, la perseverancia, el orden, el respeto, la sinceridad, la lealtad, la laboriosidad, la paciencia, la justicia, la obediencia, la humildad y el patriotismo.

El reverso de la moneda de cada una de esas virtudes es un defecto, y es necesario no acostumbrarse a esos vicios sino luchar personal y colectivamente contra ellos; el tolerar la deshonestidad, la debilidad, el pesimismo, la falta de fijeza, el desorden, la falsedad, la deslealtad, la pereza, la injusticia, la desobediencia, la soberbia y la llamada "viveza criolla" desembocan en la corrupción; "una sociedad y un país que se acostumbra a estas prácticas y actitudes y las toma como normales, es una sociedad y un país que terminan pudriéndose... No hay duda entonces que para evitar este tipo de acostumbramientos hay que desarrollar virtudes y tener ideas y principios claros en la cabeza. Ello implica formar la conciencia primero y no engañarla después" ${ }^{132}$.

Y para ello se requiere la sabiduría derivada de "la formación de uno mismo por la utilización de las virtudes: la justicia, la prudencia, la fortaleza y la 
templanza; la fe, la esperanza y la caridad que dan acceso a las tres virtudes según Platón: lo bello, lo bueno, lo verdadero"33.

\section{CONCLUSION}

Si administrar quiere decir servir, es preciso rescatar que el funcionario público es, antes que cualquier otra cosa, un servidor, sea que ocupe un cargo político de alto rango, sea que desempeñe la más modesta de las tareas.

En efecto, "la política verdadera es, sencillamente, el servicio al prójimo, a la comunidad, a aquellos que vendrán después de nosotros; su origen primitivo es moral, puesto que es fundamentalmente responsabilidad que se cumple cara a todos y por todos"34. Pero también es servicio la labor intelectual o manual que realiza cualquier funcionario.

Siendo así, es necesario jerarquizar el desenvolvimiento ético de quienes desempeñan funciones públicas, previniendo y reprimiendo las conductas corruptas. A tal fin, la efectividad de la transparencia es un supuesto y el desarrollo maduro del control social una necesidad.

Con palabras de un sabio de nuestro tiempo, el Papa Juan Pablo II, es posible epilogar estas reflexiones enfatizando que "Ante las graves formas de injusticia social y económica, así como de corrupción política que padecen pueblos y naciones enteras,... se difunde y agudiza cada vez más la necesidad de una radical renovación personal y social capaz de asegurar justicia, solidaridad, honestidad y transparencia"35.

\section{ACERCA DO CONTROLE SOCIAL DA GESTÃO PÚBLICA}

\section{RESUMO}

Após analisar a Lei Anti Corrupção do Uruguay, o autor destaca seus aspectos positivos, aseverando a necessidade da exigência da ética na administração pública, pois se administrar quer dizer servir, o funcionário é um servidor e a ética é exigência mínima a quem desempenha função de tão relevante interesse, mesmo sendo a mais modesta das tarefas.

Palabras-chave: Administração pública. Corrupção. Ética. 


\section{ABOUT THE SOCIAL CONTROL OF THE PUBLIC ADMINISTRATION}

\section{ABSTRACT}

Ater a exam of the Anti-Conrruption Law from Uruguay, the author emphasizes its positive aspects, aseverando the need for the requirement of ethics in public administration, as they manage to say serve, he is a server and ethics in the minimum requirement form who plays this such relevance role, even who those work the most modest tasks.

Keywords: Corruption. Ethic. Public Administration.

\section{NOTAS}

* Doctor en Derecho y Ciencias Sociales por la Universidad Mayor de la República Oriental del Uruguay. Profesor de Derecho Administrativo, Profesor de Informática Jurídica, y Director del Instituto de Derecho Informático en la Facultad de Derecho de dicha Universidad. Profesor de Derecho Administrativo, Director del Programa Master de Derecho Administrativo Económico (PMDAE), y Profesor de Derecho Informático en la Facultad de Derecho de la Universidad de Montevideo. Profesor Invitado del Instituto Nacional de Administración Pública (España). Profesor Visitante de la Especialización en Derecho Administrativo de la Universidad de Belgrano (Argentina). Profesor Extraordinario Visitante de la Universidad Católica de Salta (Argentina). Autor de varios libros y múltiples trabajos sobre temas de su especialidad. Miembro del Instituto Uruguayo de Derecho Administrativo, del Instituto de Derecho Administrativo de la Universidad Notarial Argentina, de la Asociación Argentina de Derecho Administrativo, de la Asociación de Derecho Público del Mercosur, de la Asociación Andrés Bello de juristas franco latino americanos, del Foro Iberoamericano de Derecho Administrativo, de la Asociación Iberoamericana de Derecho Administrativo, y de la Asociación Internacional de Derecho Administrativo.

1 Carlos E. DELPIAZZO - "Desafíos actuales del control" (F.C.U., Montevideo, 2001), pág. 7 y sigtes.

2 Carlos E. DELPIAZZO - "Etica no exercicio da funçao administrativa", en Rev. Informativo de Direito Administrativo e Responsabilidade Fiscal (Curitiba, 2001), № 5, pág. 420 y sigtes.; y "Profesionalización de la función pública en Uruguay", en La profesionalización de la función pública en Iberoamérica (Instituto de Administración Pública de España, Madrid, 2002), pág. 241 y sigtes.

3 Jesús GONZALEZ PEREZ - "La ética en la Administración pública" (Civitas, Madrid, 1996), pág. 33.

4 Jaime RODRIGUEZ-ARANA MUÑOZ - "La Etica en la modernización de las Administraciones públicas", en Rev. de Derecho Administrativo (Buenos Aires, 1999), Año 11, № 32, pág. 273.

5 Massimo Severo GIANNINI - "Control, noción y problemas en el Derecho italiano", en Anuario de Derecho Administrativo (Santiago de Chile, 1975-1976), tomo I, pág. 424.

6 Carlos E. DELPIAZZO - "Tribunal de Cuentas" (A.M.F., Montevideo, 1982), pág. 18; "El Banco Central del Uruguay" (A.M.F., Montevideo, 1998), 2ª edic. actualizada y ampliada, pág. 125 y sigtes.; "Contralor de la banca pública y privada", en Rev. de Derecho Comercial y de la Empresa (Montevideo, 1986), Año IX, № 37-40, págs. 58 y 59; y "Recursos de apelación ante la Cámara de Representantes contra actos de los Gobiernos Departamentales", en El Poder y su Control (UCUDAL, Montevideo, 1989), pág. 267. 
7 Así: Enrique SAYAGUES LASO - "Tratado de Derecho Administrativo" (Montevideo, 1959), tomo II, pág. 437, nota 3; Héctor BARBE PEREZ - "Consideraciones generales sobre la coordinación de la acción de la Administración Pública y sus instrumentos jurídicos", en Estudios jurídicos sobre la Administración Pública que surge en el Uruguay (C.E.N., Montevideo, 1970), pág. 14; Julio A. PRAT - "Derecho Administrativo" (Acali, Montevideo, 1982), tomo 5, vol. 2, pág. 113 y sigtes.; y Carlos E. DELPIAZZO y Ricardo OLIVERA GARCIA - "Contralor de la banca privada" (A.M.F., Montevideo, 1980), pág. 12.

8 Enrique SAYAGUES LASO - "Tratado..." cit., tomo II, pág. 441 y sigtes.

9 Massimo Severo GIANNINI - "Control, noción y problemas en el Derecho italiano" cit., pág. 425 y sigtes.

10 José Aníbal CAGNONI - "Introducción a la teoría del control" (Edit. Universidad, Montevideo, 1996), pág. 31.

11 Mariano R. BRITO - "Principio de legalidad e interés público en el Derecho positivo uruguayo", en La Justicia Uruguaya, tomo XC, sección Doctrina, pág. 11 y sigtes.

12 Eduardo SOTO KLOSS - "Derecho Administrativo" (Edit. Jurídica de Chile, Santiago, 1996), tomo I, pág. 83 y sigtes.; y "La primacía de la persona humana, principio fundamental del Derecho público chileno", en Estudios Jurídicos en memoria de Alberto Ramón Real (F.C.U., Montevideo, 1996), pág. 507 y sigtes.

13 Mariano R. BRITO - "Planificación y libertad en el Estado social de Derecho", en Rev. Uruguaya de Estudios Administrativos (Montevideo, 1977), № 1, págs. 35, 40 y sigtes.; y "El Estado de Derecho en una perspectiva axiológica", en lus Publicum (Universidad Santo Tomás, Santiago, 2001), № 6, pág. 63 y sigtes.

14 Carlos E. DELPIAZZO - "Desafíos actuales del control" cit., pág. 97 y sigtes.

15 Augusto DURAN MARTINEZ - "Corrupción y derechos humanos. Aspectos de Derecho administrativo", en Estudios sobre Derechos Humanos (Ingranusi, Montevideo, 1999), págs. 139 y 140.

16 Carlos E. DELPIAZZO - "Normas y principios de la contratación administrativa" (F.C.U., Montevideo, 2002), págs. 38 y 121 y sigtes.

17 Carlos E. DELPIAZZO - "La regulación legal del control social y transparencia", en Rev. de Antiguos Alumnos del IEEM, Año 5, № 1, pág. 29 y sigtes.

18 Felipe ROTONDO TORNARIA - "Aproximación a la participación del administrado a la luz de los principios generales", en Rev. de la Facultad de Derecho y C.S., Año XXVI, № 1, pág. 63.

19 Horacio CASSINELLI MUÑOZ - "El principio de publicidad de la gestión administrativa", en Rev. Derecho, Jurisprudencia y Administración, tomo 58, págs. 165 y 166.

20 Richard S WERKSMAN y Carlos MAMFRONI - "La transparencia y la Convención Interamericana contra la Corrupción", en Rev. de Derecho Administrativo (Buenos Aires, 1996), Año 8, № 21-23, pág. 346.

21 Jaime RODRIGUEZ-ARANA MUÑOZ - "La dimensión ética" (Dykinson, Madrid, 2001), pág. 312.

22 Juan Carlos CASSAGNE - "Los principios generales del Derecho en el Derecho administrativo" (Abeledo Perrot, Buenos Aires, 1988), pág. 29 y sigtes.

23 Ver: Carlos E. DELPIAZZO - "Normas y principios de la contratación administrativa" cit., pág. 27 y sigtes.

24 Ver: Carlos E. DELPIAZZO - "Transparencia y anticorrupción en la contratación pública", en Primer Congreso Internacional por Internet sobre Aspectos Jurídicos del Comercio Electrónico (www.ecomder.com.ar); y "El principio de transparencia en la contratación administrativa", en El Derecho Digital (www.elderechodigital.com.uy).

25 Luis Alberto POMED SANCHEZ - "El derecho de acceso de los ciudadanos a los archivos y registros administrativos" (M.A.P., Madrid, 1989), pág. 109 y sigtes.

26 Jaime RODRIGUEZ-ARANA MUÑOZ - "La dimensión ética" cit., pág. 319.

27 Jesús GONZALEZ PEREZ - "La ética en la Administración pública" cit., pág. 65.

28 Carlos E. DELPIAZZO - "Profesionalización de la función pública en Uruguay" cit., pág. 251 y sigtes.

29 Jesús GONZALEZ PEREZ - "La ética en la Administración pública" cit., pág. 52.

30 Carlos E. DELPIAZZO - "Profesionalización de la función pública en Uruguay" cit., pág. 256. 
31 Carlos E. DELPIAZZO - "Regulación jurídica de la ética pública", conferencia en Seminario sobre ética pública y descentralización territorial (Guatemala, 2002), de próxima publicación por el Instituto Nacional de Administración Pública (INAP) de España.

32 Nicolás ETCHEVERRY ESTRAZULAS - "Un torneo de nuestros tiempos. Etica profesional ¿por qué y para qué?", en Rev. de la Facultad de Derecho, № 17, pág. 78.

33 Jean GUITTON - "Sabiduría cotidiana. El libro de las virtudes recuperadas" (Edit. Sudamericana, Buenos Aires, 2002), pág. 164.

34 Vaclav HAVEL - "El origen moral de la política", en Rev. Empresa (Buenos Aires, 2001), № 146, pág. 70.

35 Juan Pablo II - Carta Encíclica "Veritatis Splendor", № 98.

\section{REFERÊNCIAS}

Augusto DURAN MARTINEZ - "Corrupción y derechos humanos. Aspectos de Derecho administrativo", en Estudios sobre Derechos Humanos (Ingranusi, Montevideo, 1999).

Carlos E. DELPIAZZO - "Contralor de la banca pública y privada", en Rev. de Derecho Comercial y de la Empresa (Montevideo, 1986), Año IX, № 37-40.

Carlos E. DELPIAZZO - "Desafíos actuales del control" (F.C.U., Montevideo, 2001).

Carlos E. DELPIAZZO - "El Banco Central del Uruguay" (A.M.F., Montevideo, 1998), $2^{\text {a }}$ edic. actualizada y ampliada.

Carlos E. DELPIAZZO - "Etica no exercicio da funçao administrativa", en Rev. Informativo de Direito Administrativo e Responsabilidade Fiscal (Curitiba, 2001), № 5 .

Carlos E. DELPIAZZO - "La primacía de la persona humana, principio fundamental del Derecho público chileno", en Estudios Jurídicos en memoria de Alberto Ramón Real (F.C.U., Montevideo, 1996).

Carlos E. DELPIAZZO - "La regulación legal del control social y transparencia", en Rev. de Antiguos Alumnos del IEEM, Año 5, № 1.

Carlos E. DELPIAZZO - "Normas y principios de la contratación administrativa" (F.C.U., Montevideo, 2002).

Carlos E. DELPIAZZO - "Profesionalización de la función pública en Uruguay", en La profesionalización de la función pública en lberoamérica (Instituto de Administración Pública de España, Madrid, 2002).

Carlos E. DELPIAZZO - "Recursos de apelación ante la Cámara de Representantes contra actos de los Gobiernos Departamentales", en El Poder y su Control (UCUDAL, Montevideo, 1989).

Carlos E. DELPIAZZO - "Regulación jurídica de la ética pública", conferencia en Seminario sobre ética pública y descentralización territorial (Guatemala, 2002), de próxima publicación por el Instituto Nacional de Administración Pública (INAP) de España. 
Carlos E. DELPIAZZO - "Transparencia y anticorrupción en la contratación pública", en Primer Congreso Internacional por Internet sobre Aspectos Jurídicos del Comercio Electrónico (www.ecomder.com.ar); y "El principio de transparencia en la contratación administrativa", en El Derecho Digital (www.elderechodigital.com.uy).

Carlos E. DELPIAZZO - "Tribunal de Cuentas" (A.M.F., Montevideo, 1982).

Carlos E. DELPIAZZO y Ricardo OLIVERA GARCIA - "Contralor de la banca privada" (A.M.F., Montevideo, 1980).

Eduardo SOTO KLOSS - "Derecho Administrativo" (Edit. Jurídica de Chile, Santiago, 1996), tomo I.

Enrique SAYAGUES LASO - "Tratado de Derecho Administrativo" (Montevideo, 1959), tomo II, pág. 437, nota 3

Felipe ROTONDO TORNARIA - "Aproximación a la participación del administrado a la luz de los principios generales", en Rev. de la Facultad de Derecho y C.S., Año XXVI, № 1.

Héctor BARBE PEREZ - "Consideraciones generales sobre la coordinación de la acción de la Administración Pública y sus instrumentos jurídicos", en Estudios jurídicos sobre la Administración Pública que surge en el Uruguay (C.E.N., Montevideo, 1970).

Horacio CASSINELLI MUÑOZ - "El principio de publicidad de la gestión administrativa", en Rev. Derecho, Jurisprudencia y Administración, tomo 58.

Jaime RODRIGUEZ-ARANA MUÑOZ - "La dimensión ética" (Dykinson, Madrid, 2001).

Jaime RODRIGUEZ-ARANA MUÑOZ - "La Etica en la modernización de las Administraciones públicas", en Rev. de Derecho Administrativo (Buenos Aires, 1999), Año 11, № 32.

Jean GUITTON - "Sabiduría cotidiana. El libro de las virtudes recuperadas" (Edit. Sudamericana, Buenos Aires, 2002).

Jesús GONZALEZ PEREZ - "La ética en la Administración pública" (Civitas, Madrid, 1996).

José Aníbal CAGNONI - "Introducción a la teoría del control" (Edit. Universidad, Montevideo, 1996).

Juan Carlos CASSAGNE - "Los principios generales del Derecho en el Derecho administrativo" (Abeledo Perrot, Buenos Aires, 1988).

Juan Pablo II - Carta Encíclica "Veritatis Splendor", № 98.

Julio A. PRAT - "Derecho Administrativo" (Acali, Montevideo, 1982), tomo 5, vol. 2.

Luis Alberto POMED SANCHEZ - "El derecho de acceso de los ciudadanos a los archivos y registros administrativos" (M.A.P., Madrid, 1989). 
Mariano R. BRITO - "El Estado de Derecho en una perspectiva axiológica", en lus Publicum (Universidad Santo Tomás, Santiago, 2001), № 6.

Mariano R. BRITO - "Planificación y libertad en el Estado social de Derecho", en Rev. Uruguaya de Estudios Administrativos (Montevideo, 1977), № 1.

Mariano R. BRITO - "Principio de legalidad e interés público en el Derecho positivo uruguayo", en La Justicia Uruguaya, tomo XC, sección Doctrina.

Massimo Severo GIANNINI - "Control, noción y problemas en el Derecho italiano", en Anuario de Derecho Administrativo (Santiago de Chile, 1975-1976), tomo I.

Nicolás ETCHEVERRY ESTRAZULAS - "Un torneo de nuestros tiempos. Etica profesional ¿por qué y para qué?", en Rev. de la Facultad de Derecho, № 17.

Richard S WERKSMAN y Carlos MAMFRONI - "La transparencia y la Convención Interamericana contra la Corrupción", en Rev. de Derecho Administrativo (Buenos Aires, 1996), Año 8, № 21-23.

Vaclav HAVEL - "El origen moral de la política", en Rev. Empresa (Buenos Aires, 2001), № 146.

Recebido para publicação 04/06/2008

Aceito para publicação 19/12/2008 